\title{
The influence of $\mathrm{B}_{2} \mathrm{H}_{6}$ on the growth of silicon nanowire
}

\author{
Chao-Yu Meng *, Bo-Lin Shih and Si-Chen Lee \\ Department of Electrical Engineering, Graduate Institute of Electronics Engineering, National Taiwan \\ University, Taipei, Taiwan, Republic of China; *Author for correspondence (E-mail: d89921005@ntu.edu.tw)
}

Received 19 October 2004; accepted in revised form 25 March 2005

Key words: boron-doped, growth temperature, silicon nanowire, catalyst

\begin{abstract}
The un-doped and boron-doped silicon nanowires (SiNWs) were grown via vapor-liquid-solid (VLS) mechanism by low pressure chemical deposition (LPCVD). The diameters of un-doped and boron-doped SiNWs varied from 18.5 to $75.3 \mathrm{~nm}$ and 26.6 to $66.1 \mathrm{~nm}$, respectively. The critical growth temperature of boron-doped SiNWs is $10^{\circ} \mathrm{C}$ lower than that of un-doped ones and the diameters of the boron-doped SiNWs is always larger than that of the un-doped ones under different growth temperatures. This is because that the introduction of diborane enhanced the dissociation of $\mathrm{SiH}_{4}$ which determines the growth process of SiNW. A growth process of silicon nanowire is proposed to describe the influence of $\mathrm{B}_{2} \mathrm{H}_{6}$.
\end{abstract}

\section{Introduction}

In recent years, silicon nanowires (SiNWs) are one of the focuses of intensive research and have been demonstrated to function as simple field effect transistor (FET), p-n junctions, bipolar transistors, biological and chemical sensors, and other devices (Westwater et al., 1997; Morales \& Lieber, 1998; Zhang et al., 1998, 1999, 2002; Holmes et al., 2000; Qi et al., 2003). All these devices are fabricated with either $\mathrm{P}$ or $\mathrm{N}$-type silicon nanowires and by incorporating diborane $\left(\mathrm{B}_{2} \mathrm{H}_{6}\right)$ or phosphine $\left(\mathrm{PH}_{3}\right)$ as dopant gas, silicon nanowire can be doped either $\mathrm{P}$ or $\mathrm{N}$ - type, respectively. Since the as grown silicon nanowire is naturally P-type rather than the as grown $\mathrm{N}$ type silicon wafer, it is easier to fabricate P-type SiNWs than N-type. In our works the SiNWs were grown via vapor-liquid-solid mechanism (VLS) (Frank, 1949; Webb \& Forgeng, 1957; Wagner \& Ellis, 1963, 1964, 1965; Wagner et al., 1964; Givargizov, 1975) by using Au nanoparticles with the well-controlled size as the catalyst.
Silane and diborane were used as silicon source and p-type dopant gas.

\section{Experiments}

Silicon wafers were used as the template in this study. A $200 \mathrm{~nm}$ thick buffered $\mathrm{SiO}_{2}$ were deposited on the substrate by low pressure chemical vapor deposition (LPCVD) method. Then the silicon surface was activated by poly-L-lysine from BIOCHROM AG for better adhesion between $\mathrm{Au}$ nanoparticles and silicon oxide surface. The $\mathrm{Au}$ nanoparticles in colloid solution purchased from BB International were dripped by micro-pipette on the silicon oxide surface without spinning. The quantity is about $50 \mu \mathrm{l} / \mathrm{cm}^{2}$. The VLS growth experiments were then carried out in an isothermal 8 -inch diameter cylindrical quartz tube reactor. The system was degassed under vacuum and purged with $\mathrm{N}_{2}$ and then heated to the growth temperature. The growth temperature is chosen initially at $420^{\circ} \mathrm{C}$ and raised $10^{\circ} \mathrm{C}$ a step to look for 
the temperature at which the SiNWs started to grow. A $10 \%$ diluted $\mathrm{SiH}_{4}$ was then introduced into the tube to initiate the SiNWs growth. The flow rate of $\mathrm{SiH}_{4}$ was $400 \mathrm{sccm}$ and the total pressure was kept at 30 Torr during the growth. As for the growth of boron-doped SiNWs the flow rate of $\mathrm{SiH}_{4}$ and $\mathrm{B}_{2} \mathrm{H}_{6}$ was 400 and $50 \mathrm{sccm}$, respectively, and the total pressure was also kept at 30 Torr. Planar view images of SiNWs after VLS growth were performed with a $5 \mathrm{kV}$ LEO 1530 scanning electron microscope (SEM).

\section{Results and discussion}

Un-doped and boron-doped SiNWs were successfully grown via VLS mechanism starting at $450^{\circ} \mathrm{C}$ and $440^{\circ} \mathrm{C}$, respectively. The SEM pictures of undoped SiNWs grown at $440^{\circ} \mathrm{C}$ and $450^{\circ} \mathrm{C}$ using 20$\mathrm{nm}$ diameter $\mathrm{Au}$ nanoparticles as the catalyst are shown in Figure 1(a) and (b), respectively. The TEM picture showing the lattice image of SiNW near the $\mathrm{Au}$ nanoparticle of Figure 1(b) is displayed in Figure 1(c). Figure 1(d) and (e) show the boron-doped SiNWs grown at $430^{\circ} \mathrm{C}$ and $440^{\circ} \mathrm{C}$, respectively. It was found that the critical temperature of boron-doped SiNWs is lower than that of un-doped SiNWs. The VLS mechanism is inferred that the $\mathrm{SiH}_{4}$ gas adsorbed at the surface of Au nanoparticles. Then the dehydrogenation of $\mathrm{SiH}_{4}$ occurred at the surface of the Au nanoparticles. The dissociated $\mathrm{Si}$ atoms dissolved into the $\mathrm{Au}$ nanoparticles to reach supersaturation and precipitated to form SiNWs at critical temperature. Hence the influence of the introduction of $\mathrm{B}_{2} \mathrm{H}_{6}$ during SiNWs growth can be explained from the view point of dehydrogenation of $\mathrm{SiH}_{4}$. The reaction mechanism for the adsorption of $\mathrm{SiH}_{4}$ and the subsequent elimination of hydrogen is (Hitchman \& Jensen, 1993)

$$
\begin{aligned}
& \mathrm{SiH}_{4(\mathrm{~g})}+2 \mathrm{~s} \rightarrow \mathrm{H}+\mathrm{SiH}_{3} \\
& \mathrm{SiH}_{3}+\mathrm{s} \rightarrow \mathrm{H}+\mathrm{SiH}_{2} \\
& 2 \mathrm{SiH}_{2} \rightarrow \mathrm{H}_{2(\mathrm{~g})}+2 \mathrm{SiH} \\
& 2 \mathrm{SiH} \rightarrow \mathrm{H}_{2(\mathrm{~g})}+2 \mathrm{~s}+\mathrm{Si} \mathrm{film} \\
& 2 \mathrm{H} \rightarrow \mathrm{H}_{2(\mathrm{~g})}+2 \mathrm{~s}
\end{aligned}
$$

Here s refers to vacant sites and underline designates the adsorbed species. Below $500^{\circ} \mathrm{C}$ the growth rate is limited by reaction (a) and the introduction of $\mathrm{B}_{2} \mathrm{H}_{6}$ will enhance reaction (a). Since at lower temperature, the decomposition of $\mathrm{B}_{2} \mathrm{H}_{6}$ into $\mathrm{BH}_{3}$ is more probable than dissociation of $\mathrm{SiH}_{4}$ because of lower dissociation energy of $\mathrm{B}_{2} \mathrm{H}_{6}$ (Perrin et al., 1989; Yang et al., 1989; Rablen \& Hartwig, 1996; Rablen 1997). Thus during the growth of boron-doped SiNWs the $\mathrm{B}_{2} \mathrm{H}_{6}$ first dissociated into $\mathrm{BH}_{3}$ with the reaction formula: $\mathrm{B}_{2} \mathrm{H}_{6}(\mathrm{~g}) \rightarrow 2 \mathrm{BH}_{3}(\mathrm{~g})$. Then $\mathrm{SiH}_{4}$ and $\mathrm{BH}_{3}$ combine to form a $\mathrm{SiH}_{4}-\mathrm{BH}_{3}$ complex in the CVD mechanism, with the $\mathrm{SiH}_{4}$ behaving as an electron donor and $\mathrm{BH}_{3}$ as an electron acceptor. It was indicated that the complex dimer $\mathrm{SiH}_{4}-\mathrm{BH}_{3}$ is easily dissociate into $\mathrm{SiH}_{3}$ and $\mathrm{BH}_{4}$ radicals $(\mathrm{Hu}$ et al., 2002). Hence the reaction (a) is enhanced. Thus the critical growth temperature of borondoped SiNWs becomes lower than that of un-doped SiNWs.

Another remarkable feature could be obtained by observing the morphology of un-doped and boron-doped SiNWs grown at the higher growth temperature. Figure 2 shows the dependence of the diameter of SiNWs grown with $20 \mathrm{~nm} \mathrm{Au}$ nanoparticles as the catalyst on the deposition temperature, respectively. It is clear that the diameter of p-doped SiNWs becomes thicker than those of undoped SiNWs due to their faster lateral growth rate at the same deposition temperature. This result could also explain the fact that the critical temperature of boron-doped SiNWs is lower than that of un-doped SiNWs. The SEM pictures of $490^{\circ} \mathrm{C}$ and $510^{\circ} \mathrm{C}$ grown un-doped and $550^{\circ} \mathrm{C}$ and $600^{\circ} \mathrm{C}$ grown boron-doped SiNWs are shown in Figure 3(a) and (b), respectively. The density of un-doped SiNWs dropped rapidly at $510^{\circ} \mathrm{C}$ because the $\mathrm{SiH}_{4}$ molecules were dissociated in the gas, and the $\mathrm{Si}$ atom arriving at the surface of the $\mathrm{Au}$ nanoparticles were too fast resulting in the deposition of amorphous-Si on the surface of $\mathrm{Au}$ nanoparticles which retarded the growth of SiNWs. This phenomenon is also observed in boron-doped case. But the temperature that the density of boron-doped SiNWs decreased significantly is much higher, i.e., $\sim 600^{\circ} \mathrm{C}$. This can be also explained by the dissociation rate of $\mathrm{SiH}_{4}$. The $\mathrm{B}_{2} \mathrm{H}_{6}$ enhanced the dissociation of $\mathrm{SiH}_{4}$ leads to the faster growth rate of boron-doped SiNWs. Thus the dissociation rate of $\mathrm{SiH}_{4}$ in the gas must be further raised to retard the growth of 

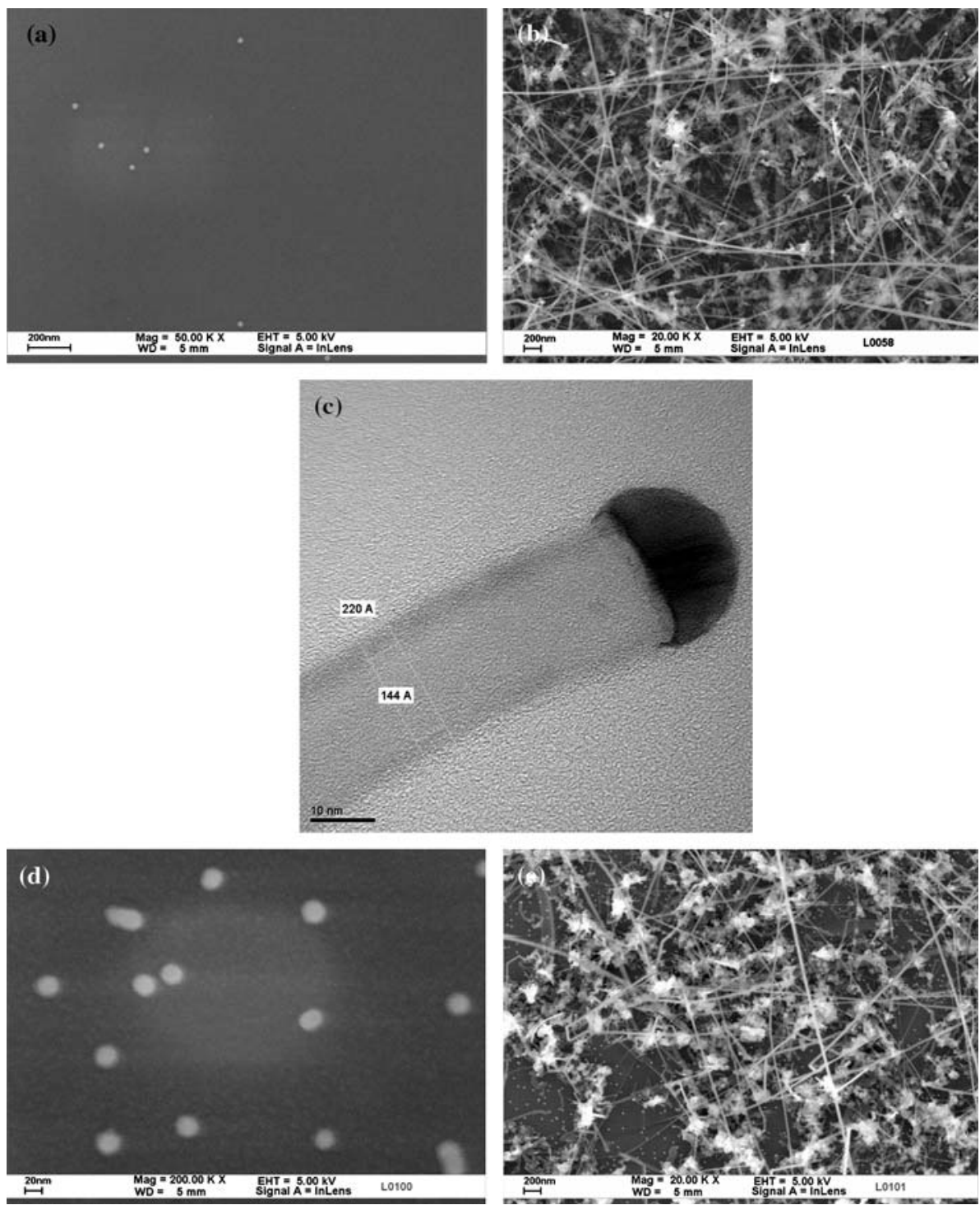

Figure 1. The SEM pictures of un-doped SiNWs grown at (a) $440^{\circ} \mathrm{C}$ and (b) $450^{\circ} \mathrm{C}$. (c) The TEM picture of sample shown in (b). The SEM picture of boron-doped SiNWs grown at (d) $430^{\circ} \mathrm{C}$ and (e) $440^{\circ} \mathrm{C}$ using $20 \mathrm{~nm}$ Au nanoparticles as the catalyst.

boron-doped SiNWs. Although the $\mathrm{B}_{2} \mathrm{H}_{6}$ enhanced the dissociation of $\mathrm{SiH}_{4}$ whether in the gas or on the Au nanoparticles surface, it seems that the change of $\mathrm{SiH}_{4}$ dissociation rate on the $\mathrm{Au}$ nanoparticles surface is more significant than that in the gas at lower temperature $\left(<550^{\circ} \mathrm{C}\right)$. However the dissociation of $\mathrm{SiH}_{4}$ in the gas becomes dominant at higher temperature, i.e. $>550^{\circ} \mathrm{C}$. Hence the amorphous-Si are formed and deposited to suppress boron-doped SiNWs growth. HRTEM images were shown as the evidence to illustrate the growth phenomenon in Figure 4(a)-(c). The Au catalyst used is $20 \mathrm{~nm}$ and the growth temperature of boron-doped SiNWs is $450^{\circ} \mathrm{C}, 470^{\circ} \mathrm{C}$ and $490^{\circ} \mathrm{C}$, respectively. The inset shows the electron diffraction patterns of the SiNWs, respectively. It is clear from Figure 2 that the diameter of SiNWs dosen't change with the rise of process temperature until $480^{\circ} \mathrm{C}$. And the HRTEM image and electron diffraction patterns in Figure 4(c) show 


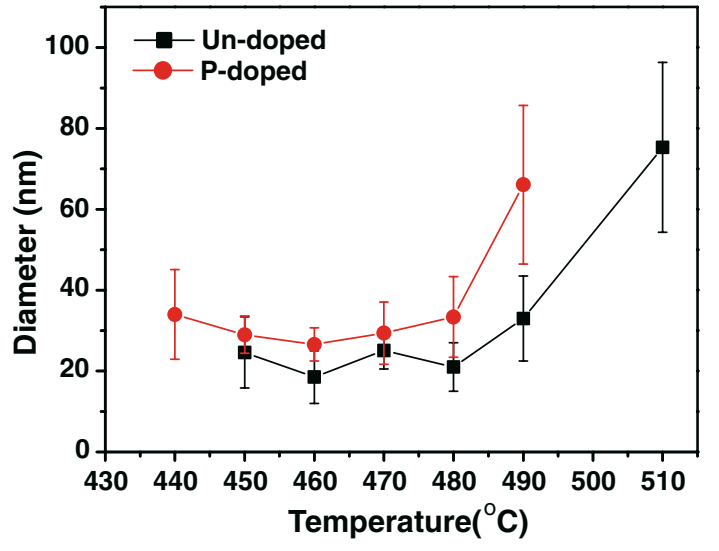

Figure 2. The diameter of un-doped and P-doped SiNWs grown with $20 \mathrm{~nm} \mathrm{Au}$ nanoparticles as the catalyst versus deposition temperature.

that there exists an amorphous shell outside the single crystal SiNW. Once the growth temperature exceeds $480^{\circ} \mathrm{C}$, the $\mathrm{B}_{2} \mathrm{H}_{6}$ assisted dissociation process will start not only on the Au surface but also on other place and lead to the coating of
SiNWs. The deposition or coating rate of amorphous-Si will increase the diameter of SiNWs as the process temperature increase and result in the rapid slope change in Figure 2. The growth windows which are defined to be the temperature range that the un-doped and boron-doped SiNWs kept its diameter the same as Au catalyst are determined and listed in Table 1. For the undoped SiNWs, the growth process starts at $450^{\circ} \mathrm{C}$ and rapidly increases lateral growth after $490^{\circ} \mathrm{C}$. For the boron-doped SiNWs, the growth process starts at $440^{\circ} \mathrm{C}$ and rapidly increases lateral growth after $480^{\circ} \mathrm{C}$. And the stopping growth of

Table 1. The growth window of un-doped and borondoped SiNWs using $20 \mathrm{~nm}$ Au nanoparticles as the catalyst

\begin{tabular}{lll}
\hline & $\begin{array}{l}\text { Un-doped } \\
\text { SiNWs }\end{array}$ & $\begin{array}{l}\text { Boron-doped } \\
\text { SiNWs }\end{array}$ \\
\hline Start to grow $\left({ }^{\circ} \mathrm{C}\right)$ & 450 & 440 \\
Start to coat $\left({ }^{\circ} \mathrm{C}\right)$ & 490 & 480 \\
Stop growing $\left({ }^{\circ} \mathrm{C}\right)$ & 510 & 600 \\
\hline
\end{tabular}
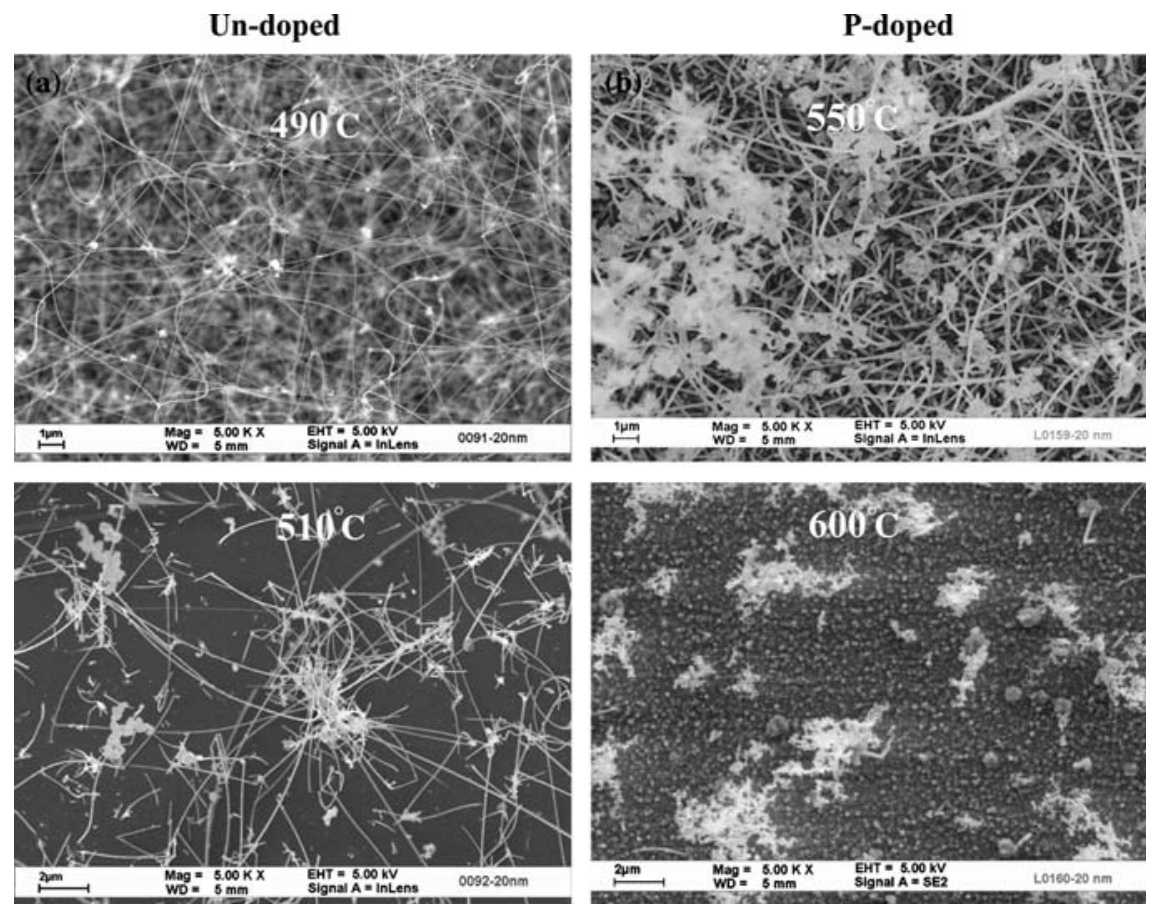

Figure 3. The SEM pictures of (a) un-doped SiNWs grown at $490^{\circ} \mathrm{C}$ and $510^{\circ} \mathrm{C}$, (b) boron-doped SiNWs grown at $550^{\circ} \mathrm{C}$ and $600^{\circ} \mathrm{C}$ with $20 \mathrm{~nm} \mathrm{Au}$ nanoparticles as the catalyst. 

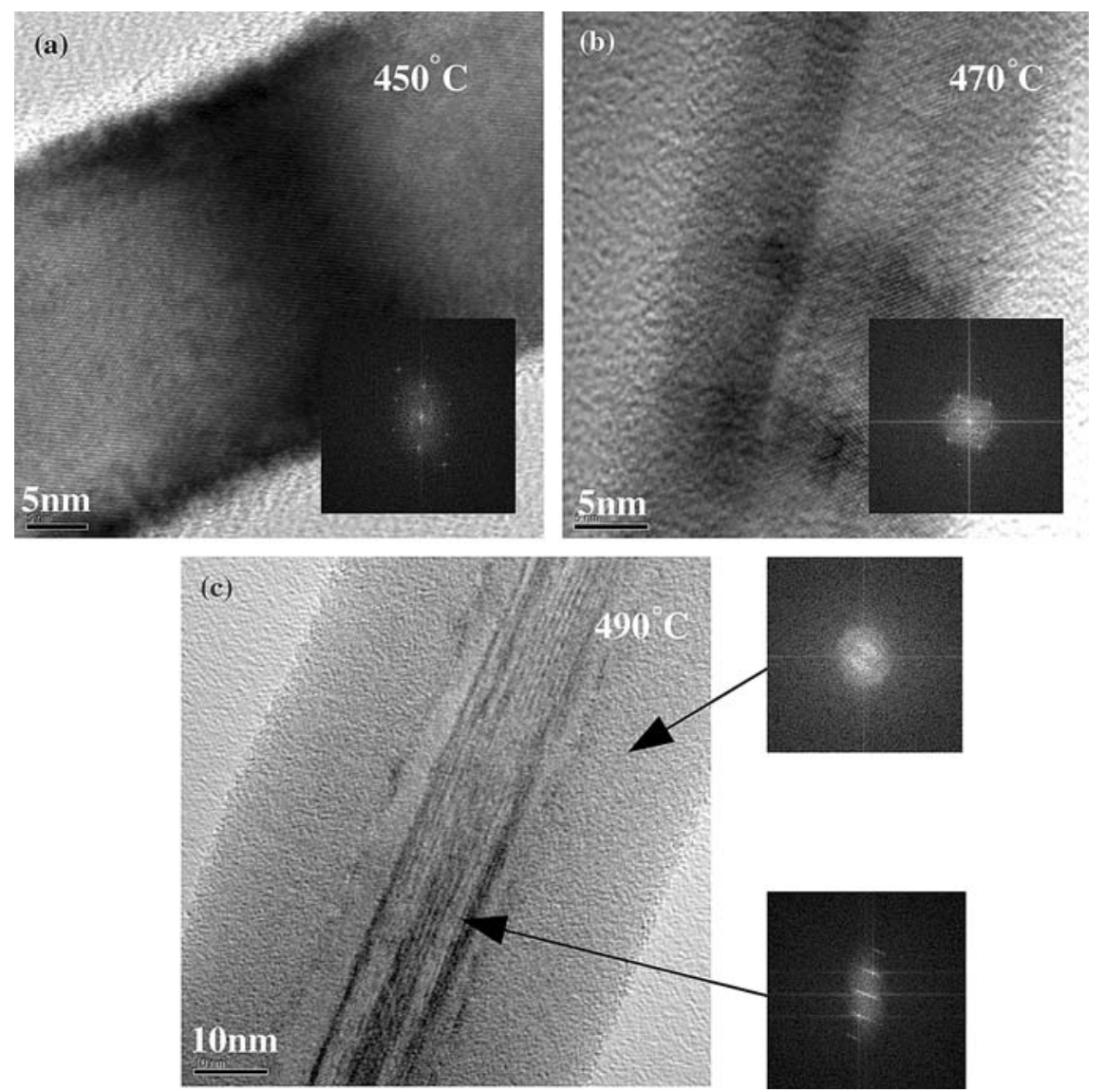

Figure 4. The TEM pictures of boron-doped SiNWs grown at (a) $450^{\circ} \mathrm{C}$, (b) $470^{\circ} \mathrm{C}$ and (c) $490^{\circ} \mathrm{C}$ with $20 \mathrm{~nm}$ Au nanoparticles as the catalyst.

un-doped and boron-doped SiNWs are also shown in Table 1 as $510^{\circ} \mathrm{C}$ and $600^{\circ} \mathrm{C}$, respectively.

\section{Conclusions}

In conclusion, the enhancement of dissociation of $\mathrm{SiH}_{4}$ under the introduction of $\mathrm{B}_{2} \mathrm{H}_{6}$ is reasonably explained. This effect is due to the reaction of transient complex product $\mathrm{SiH}_{4}-\mathrm{BH}_{3}$ and result in the $10^{\circ} \mathrm{C}$ process temperature shift. The growth windows of un-doped and boron-doped SiNWs were also found. The growth window for un-doped SiNWs is start from $450^{\circ} \mathrm{C}$ to $490^{\circ} \mathrm{C}$ and for borondoped SiNWs is start from $440^{\circ} \mathrm{C}$ to $480^{\circ} \mathrm{C}$, respectively. The cause for rapidly increase in diameter is due to the increased dissociation rate of $\mathrm{SiH}_{4}$ in the air, which will deposit and coat on the surface of SiNWs and further increase the diameter. For the boron-doped SiNWs, the growing process end up at $600^{\circ} \mathrm{C}$ which is $90^{\circ} \mathrm{C}$ higher than the undoped SiNWs which is due to the asymmetrical increment of $\mathrm{SiH}_{4}$ dissociation rate on Au catalyst surface and in the air, respectively.

\section{Acknowledgements}

This work has been supported by the Industrial Technology Research Institute.

\section{References}

Frank F.C., 1949. Discussion Faraday Soc. 108, 649.

Givargizov E.I., 1975. J. Chem. Phys. 31, 20.

Hitchman M.L. \& K.F. Jensen, 1993. Chemical Vapor Deposition: Principle and Application. London: Academic Press. 
Holmes J.D., K.P. Johnston, R.C. Doty \& B.A. Korgel, 2000 Science 287, 1471.

Hu S., J. Kim, P. Tarakeshwar \& K.S. Kim, 2002. J. Phys. Chem A 106, 6817.

Morales A.M. \& C.M. Lieber, 1998. Science 279, 208.

Perrin J., Y. Takeda \& Y. Takeuchi, 1989. Surface. Sci. 210, 114.

Qi J., A.M. Belcher \& J.M. White, 2003. Appl. Phys. Lett. 82, 2616.

Rablen P.R. \& J.F. Hartwig, 1996. J. Am. Chem. Soc. 118, 4648 .

Rablen P.R., 1997. . J. Am. Chem. Soc. 119, 8350.

Wanger R.S. \& W.C. Ellis, 1965. Appl. Phys. Lett. 4, 89.

Wagner R.S. \& W.C. Ellis, 1964. Appl. Phys. Lett. 4, 89.
Wagner R.S., W.C. Ellis, K.A. Jackson \& S.M. Arnold, 1964. J. Appl. Phys. 35, 2993.

Wagner R.S. \& W.C. Ellis, 1963. J. Metals 15, 76.

Webb W.W. \& W.D. Forgeng, 1957. J. Appl. Phys. 28, 1449.

Westwater J., D.P. Gosain, S. Tomiya \& S. Usui, 1997. J. Vac. Sci.Technol B 15, 554.

Yang G., P. Bai, B.Y. Tong, S.K. Wong \& I. Hill, 1989. Solid State Commun. 72, 159.

Zhang Y.F., Y.H. Tang, H.Y. Peng, N. Wang, C.S. Lee, I. Bello \& S.T. Lee, 1998. Appl. Phys. Lett. 73, 3396.

Zhang Y.F., Y.H. Tang, H.Y. Peng, N. Wang, C.S. Lee, I. Bello \& S.T. Lee, 1999. Appl. Phys. Lett. 75, 1842.

Zhang S.L., W. Ding, Y. Yan, J. Qu, B. Li, L.Y. Li, K.T. Yue \& D. Yu, 2002. Appl. Phys. Lett. 81, 4446. 